\title{
First and second transscleral cyclophotocoagulation treatments provide similar intraocular pressure-lowering efficacy in patients with refractory glaucoma
}

\author{
Enrico Bernardi · Marc Töteberg-Harms
}

Received: 13 September 2021 / Accepted: 12 January 2022 / Published online: 3 February 2022

(C) The Author(s) 2022, corrected publication 2022

\begin{abstract}
Purpose The aim of this study is to address the safety and effectiveness of a second continuous-wave transscleral cyclophotocoagulation (CW-TSCPC) treatment by comparing its outcome against a first CW-TSCPC treatment in the same patients with refractory glaucoma.

Methods Twenty-one eyes with either primary or secondary glaucoma received a second CW-TSCPC laser session $\geq 3$ months after the first treatment. Intraocular pressure (IOP), best-corrected visual acuity (BCVA), and number of topical or oral ophthalmic pressure-reducing medications were registered at every time point up to the last follow-up at 3 months. A complete slit-lamp examination was conducted to record for complications or other abnormal ocular findings. Success was defined as IOP between 6 and $21 \mathrm{mmHg}$ and $>20 \%$ reduction in IOP with or without anti-glaucoma medications.
\end{abstract}

E. Bernardi · M. Töteberg-Harms

Medical Faculty, University of Zurich, Zurich, Switzerland

E. Bernardi · M. Töteberg-Harms ( $\square)$

Department of Ophthalmology, University Hospital Zurich, Frauenklinikstrasse 24, 8091 Zurich, Switzerland e-mail: MarcToeteberg@aol.com

M. Töteberg-Harms

Medical College of Georgia, Department of Ophthalmology, Augusta University, Augusta, GA, USA
Results At 3 months follow-up of the first CWTSCPC treatment, a $24.8 \%$ decrease in IOP was observed, whereas a $45.6 \%$ IOP decrease was observed 3 months post the second CW-TSCPC treatment. Visual acuity did not decrease, and no major complications were observed post either treatment within the follow-up period. Time to failure was $79.5 \pm 24.6$ and $77.1 \pm 29.4$, respectively $(P=0.955)$. No serious complications were observed.

Conclusion A second CW-TSCPC treatment proved to be a safe and effective treatment option when the first CW-TSCPC treatment was insufficient in maintaining the desired IOP level for a prolonged time (mean time between both sessions $6.4 \pm 8.0$ months).

Keywords Glaucoma - Cyclophotocoagulation · G-Probe $\cdot \mathrm{CPC} \cdot \mathrm{CW}-\mathrm{TSCPC}$

\section{Introduction}

Glaucoma is a chronic, progressive optic neuropathy with a multi-factorial etiology [1-5]. It is the leading cause of irreversible blindness worldwide [6-8]. An irreversible damage of the optic nerve and a progressive loss of nerve fibers causes vision loss [9-11]. However, an appropriate and timely therapy can effectively prevent progressive nerve damage, loss of visual field, and thus blindness [12-15]. In most cases, glaucoma is associated with a pathological 
increase of intraocular pressure (IOP) $(>21 \mathrm{mmHg}$ ), and, therefore, therapies are aimed at reducing IOP $[16,17]$.

There are several ways of achieving IOP reduction: (1) medical treatment (mostly topical eye drops), (2) surgical procedures (incisional surgeries and minimally invasive glaucoma surgery (MIGS) procedures), or (3) lasers (i.e., laser trabeculoplasty, endocyclophotocoagulation, cyclophotocoagulation) [18-21].

Continuous-wave transscleral cyclophotocoagulation (CW-TSCPC) using the G-Probe ${ }^{\circledR}$ delivery device (IRIDEX Corp., Mountain View, CA, USA) is an established procedure that achieves IOP reduction through destruction of the pigmented cells within the ciliary body to decrease aqueous humor production [22-26]. This approach uses energy administered with an $810 \mathrm{~nm}$ continuous-wave laser [27, 28]. The energy is absorbed by the melanin present in the pigmented epithelium of the ciliary body and leads to an increase in temperature, which causes coagulation. A "pop" sound can be heard once coagulation is reached in the target pigmented epithelium. The energy should be kept just below this "pop" level [29]. Unfortunately, this modality also increases thermal elevation to the surrounding tissue causing a high degree of collateral damage. In addition, it is known that there is variation in the location of the pigmented epithelium of the ciliary body from eye to eye, and within one eye, which causes unpredictability of treatment success to some degree. Common complications of CW-TSCPC are persistent intraocular inflammation, hyphema, cystoid macular edema, decreased visual acuity or vision loss, and persistent hypotony (phthisis bulbi) [30]; hence, its use is usually limited to refractory glaucomas.

Patients sometimes require a second CW-TSCPC treatment to achieve the desired IOP reduction and successfully retain it over time. In previous studies, the retreatment rate ranged from 0 to $81 \%$ [31-35]; however, numerous CW-TSCPC retreatments come with an increased risk of side effects. Previously treated eyes may tend to react to the coagulative laser energy with an excessive inflammatory response. Given the factors involved with reoperations, the rate at which they occur has been proposed as an indicator of the quality of care and a marker of surgical quality [36, 37]. Managing complications may have social, occupational, and financial consequences to the patient and society while also increasing the surgical cost and clinical burden for the hospital or clinic. This is especially true within the first 90 days, which is the time frame most insurance companies consider as the postoperative "global period," or the time considered by where no additional reimbursement will be paid to manage complications [38].

The efficacy of subsequent CW-TSCPC retreatment has not been widely addressed in the literature and, thus, is the aim of this study.

\section{Materials and methods}

This is a retrospective, comparative interventional chart-review of patients with various diagnosis of glaucoma who received two treatment sessions of CW-TSCPC at the University Hospital Zurich, Zurich, Switzerland. The cantonal ethics commission of Zurich granted its approval to the study protocol and the study follows the principles of the Declaration of Helsinki and international and national laws. As stated in the protocol and according to the Art. 34 Human Research Act, the patients considered for this study signed either a general consent for research before the operation or an adapted consent specific for this study.

\section{Inclusion and exclusion criteria}

Surgeries were performed between 03/2016 and $01 / 2020$. Patients selected for the study had either primary or secondary glaucoma and were diagnosed with moderate to advanced glaucoma. Patients had prior, failed glaucoma surgery and non-controlled IOP on maximum tolerated meds (refractory glaucoma) or had advanced glaucoma with poor BCVA (i.e., $\leq 0.2$ Decimal Snellen) and/or advanced, central involving visual field defects and non-controlled IOP on maximum tolerated meds. Patients who were underage at the time of the operation or who did not provide their agreement with either the general consent or the study-specific consent were automatically excluded from the study. In addition, patients were excluded when the second CWTSCPC treatment was performed less than 3 months after the first. 
Procedure, anesthesia, and postoperative care

All procedures were performed by one glaucoma specialist (MTH). Immediately prior to CW-TSCPC, all patients received intravenous analgesia $(50 \mathrm{mg}$ fentanyl) and sedation (1-1.5 mg/kg body weight thiopental sodium $0.5 \mathrm{~g} / 20 \mathrm{ml}$ ) under monitored anesthesia care. The G-Probe handpiece was used with the IRIDEX Cyclo G6 ${ }^{\mathrm{TM}}$ Laser System (Iridex Corp., Mountain View, CA, USA). The Cyclo G6 was set in its continuous-wave treatment mode, and power was set to $2000 \mathrm{~mW}$ for $2500 \mathrm{~ms}$ per laser spot. Fifteen laser spots were applied, sparing the superior aspect of the globe from 10 to 2 o'clock. Two percent methylcellulose (Methocel, OmniVision, Puchheim, Germany) was used to guarantee a liquid interface. Care was taken to avoid the 3 o'clock and 9 o'clock meridians, areas of scleral thinning, sites of filtering blebs, and sites of glaucoma drainage devices. As the same protocol was used for the first CW-TSCPC treatment, treatment locations would potentially be at the same location where a laser spot was applied during the first treatment. If a "scleral spot" was seen from the first laser treatment, the spot during the second treatment was placed slightly apart from the visible scleral spot. After the treatment, the eye was patched for $24 \mathrm{~h}$ with a fixed combination ointment of tobramycin $3 \mathrm{mg} / \mathrm{ml}$ plus dexamethasone $1 \mathrm{mg} / \mathrm{ml}$ (Tobradex ointment; Alcon, Fort Worth, TX, USA). The next day, patients were started on unpreserved dexamethasone $1 \mathrm{mg} / \mathrm{ml}$ eye drops $5 \mathrm{x} / \mathrm{d}$ for 1 week (Dexafree UD eye drops; Théa PHARMA SA, Schaffhausen, Switzerland) and unpreserved ofloxacin eye drops $3 \mathrm{x} / \mathrm{d}$ for 3 days (Floxal UD eye drops; Bausch \& Lomb Swiss AG, Zug, Switzerland). All patients were instructed to continue with their preoperative anti-glaucoma medication regimen. Medical hypotensive treatment was adjusted for each patient at every visit and was reduced, whenever possible, in a stepwise approach and at the surgeon's discretion.

Baseline and follow-up data collection

To evaluate and compare the efficacy of the first versus the second CW-TSCPC treatments, data collected at baseline included age at the time of surgery, sex, type of glaucoma, number of glaucoma medications (topical and oral ophthalmic pressure-reducing medications; meds), IOP (obtained through Goldmann applanation tonometry), best-corrected visual acuity (BCVA), and spherical equivalent. The participants underwent follow-up visits at 1 day, 1 week, 1 month, and 3 months postoperatively. At each postoperative appointment, the following factors were registered: spherical equivalent, IOP, BCVA, and meds. Simultaneously, a complete slit-lamp examination was conducted to record the following complications: corneal edema, persistent ocular hypotony (i.e., IOP $\leq 5 \mathrm{mmHg}$ ) on two consecutive follow-up visits, choroidal detachment, phthisis bulbi, sympathetic ophthalmia, cystoid macular edema, or any other abnormal ocular findings. A loss of vision of two or more lines in BCVA compared to baseline or a loss of light perception vision was also noted and considered as a complication.

Statistical analyses

Excel 2016 was used for data management and IBM SPSS Statistics (International Business Machines Corporation (IBM), Armonk, NY, USA) version 26 was used for statistical analysis. Descriptive statistics were reported as mean \pm SD for continuous variables and as absolute values and percentage for categorical variables. Preoperative and postoperative data were compared using student's $t$ test for equality of means (continuous variables) and chi-square test (categorical variables). A $P$ value of $<0.05$ was considered to be statistically significant. Differences in survival were assessed by Kaplan Meier survival statistics. Differences in survival between the two groups were computed using Log Rank (Mantel-Cox) statistics. Success was defined as either an IOP between 6 and $21 \mathrm{mmHg}$ at the last visit and an IOP reduction of $>20 \%$ compared to the baseline measurement.

\section{Results}

In total, 21 eyes of 21 patients were treated with CW-TSCPC two consecutive times within the time frame of the study. The mean time between both CWTSCPC sessions was $6.4 \pm 8.0$ months. The average age was $64.7 \pm 16.5$ years; gender was $71.4 \%$ males and $28.6 \%$ females; eyes were $33.3 \%$ right and $66.7 \%$ left; and the diagnosis was $14.3 \%$ primary open-angle glaucoma, $42.9 \%$ pseudoexfoliative glaucoma, and $42.9 \%$ other glaucoma types (Table 1). The mean 
Table 1 Demographical data

\begin{tabular}{ll}
\hline & CW-TSCPC 1 and 2 \\
\hline Eyes & 42 \\
& OD 14 (33.3\%) \\
OS 28 (66.7\%) & $64.8 \pm 16.2$ years \\
Mean age [years] & 30 males (71.4\%) \\
Gender & 12 females $(28.6 \%)$ \\
& $-2.82 \pm 3.5$ \\
Spherical Equivalent & $2.7 \pm 0.3$ \\
Baseline BCVA & $33.2 \pm 7.3$ \\
Baseline IOP [mmHg] & $2.8 \pm 1.1$ \\
Baseline AGD & $6(14.3 \%)$ \\
Diagnosis & $18(42.9 \%)$ \\
Primary open-angle glaucoma & $18(42.9 \%)$ \\
Pseudoexfoliative glaucoma & \\
Other glaucomas & \\
\hline
\end{tabular}

$O D$ right eye, $O S$ left eye, $B C V A$ best-corrected visual acuity, $\log M A R$ logarithm of the minimum angle of resolution, $I O P$ intraocular pressure, $\mathrm{mmHg}$ millimeters of mercury, $V F M D$ visual field mean defect, $d B$ decibel

baseline IOP was $35.1 \pm 16.3 \mathrm{mmHg}$ before the first CW-TSCPC treatment and $31.4 \pm 12 \mathrm{mmHg}$ before the second CW-TSCPC treatment.

The first CW-TSCPC treatment achieved a 34.3\% reduction in IOP compared to baseline at day one $(P<0.001), 43.4 \%$ at 1 week $(P<0.001), 29.8 \%$ at 1 month $(P<0.001)$, and $24.8 \%$ at 3 months $(P=0.009)$. The second CW-TSCPC treatment achieved an IOP reduction of $13.2 \% 1$ day postoperatively $(P=0.308), 48.3 \%$ at 1 week $(P=0.317)$, $32.2 \%$ at 1 month $(P=0.459)$, and $45.6 \%$ at 3 months $(P=0.023)$. Notably, no loss of vision and no other serious complications occurred after either treatment. At baseline, meds were slightly higher at the time of the first CW-TSCPC treatment than at the time of the second treatment $(3.0 \pm 1.4$ vs. $2.5 \pm 1.5 ; P=0.249)$. The decrease in meds at 3 months was $21.3 \%$ after the first treatment and $14.4 \%$ following the second treatment $(P=0.991)$. At 3 months, there was a significant difference in IOP reduction between the two groups, with the second CW-TSCPC treatment showing a greater decrease in IOP (45.6 vs. $24.8 \%, P=0.001$ ). The baseline IOP was slightly lower among patients before the second CW-TSCPC treatment $(31.4 \pm 12 \mathrm{mmHg})$ compared to the first CW-TSCPC treatment $(35.1 \pm 16.3 \mathrm{mmHg}$ ) (Table 2). Time to failure after the first CW-TSCPC was $79.5 \pm 24.6$ days and $77.1 \pm 29.4$ after the second CW-TSCPC treatment. No statistically significant difference in success between the first CW-TSCPC and the second CWTSCPC treatments was found $(P=0.955)$.

\section{Discussion}

Based on the findings of this study, a second CWTSCPC proved to be effective in terms of survival of success and more effective in terms of lowering IOP compared to the first CW-TSCPC treatment. Both procedures achieved a significant decrease in IOP compared to preoperative IOP at all visits. At the same time, meds were significantly reduced and were lower at all visits in comparison to baseline, with the exception of 1 week after the second procedure. Kaplan-Meier survival did not differ significantly between the first and second CW-TSCPC treatments; therefore, a second CW-TSCPC treatment is noninferior to a first treatment. No serious complications occurred during the follow-up period of this study.

Potentially, a second CW-TSCPC treatment could be less effective compared to the first treatment. The

Table 2 Preoperative and postoperative data for BCVA, IOP, and Meds

\begin{tabular}{|c|c|c|c|c|c|c|c|c|c|}
\hline & \multicolumn{2}{|c|}{ BCVA [logMAR] } & \multirow[b]{2}{*}{$P$} & \multicolumn{2}{|l|}{ IOP [mmHg] } & \multirow[b]{2}{*}{$P$} & \multicolumn{2}{|l|}{ Medications } & \multirow[b]{2}{*}{$P$} \\
\hline & 1st CW-TSPC & 2nd CW-TSPC & & 1st CW-TSPC & 2nd CW-TSPC & & 1st CW-TSPC & 2nd CW-TSPC & \\
\hline Baseline & $2.8 \pm 3.8$ & $2.7 \pm 3.6$ & 0.975 & $35.1 \pm 16.3$ & $31.4 \pm 12.0$ & 0.403 & $3.1 \pm 1.4$ & $2.5 \pm 1.5$ & 0.249 \\
\hline 1 day & $2.8 \pm 3.7$ & $4.3 \pm 4.4$ & 0.319 & $23.1 \pm 11.3$ & $27.2 \pm 13.4$ & 0.308 & 0 & 0 & - \\
\hline 1 week & $3.4 \pm 4.2$ & $4.4 \pm 4.5$ & 0.472 & $219.9 \pm 13.7$ & $16.2 \pm 8.5$ & 0.324 & $2.7 \pm 1.4$ & $2.6 \pm 1.6$ & 0.781 \\
\hline 1 month & $2.7 \pm 3.7$ & $3.4 \pm 4.2$ & 0.595 & $24.6 \pm 15.0$ & $21.3 \pm 13.0$ & 0.457 & $2.5 \pm 1.6$ & $2.4 \pm 1.5$ & 0.783 \\
\hline 3 months & $1.0 \pm 1.0$ & $3.3 \pm 4.1$ & $<0.001$ & $26.4 \pm 13.0$ & $16.7 \pm 6.8$ & 0.001 & $2.4 \pm 1.4$ & $2.1 \pm 1.4$ & 0.991 \\
\hline
\end{tabular}

$B C V A$ best-corrected visual acuity, $\log M A R$ logarithm of the minimum angle of resolution, $I O P$ intraocular pressure, $m m H g$ millimeters of mercury 
hypothesis is that during the second CW-TSCPC treatment, the laser would be applied at the same locations of the ciliary body as the primary treatment, which have already been coagulated. Thus, no additional decrease in aqueous humor production by the second laser spots can be expected since the tissue in this location has already been destroyed. Despite this consideration, the presented data demonstrate comparable effectiveness between first and second CWTSCPC treatments.

This finding is crucial since the first CW-TSCPC treatment sometimes does not lower IOP sufficiently to reach a preset target pressure or suffice in maintaining a desirable IOP level for a prolonged time. A second laser treatment being as effective as a first treatment grants ophthalmologists more options when deciding how to further lower IOP when the first operation proved to be not effective enough; otherwise, more invasive treatments, e.g., tube shunts, must be discussed with the patients. In our data, we did not find a higher risk for hypotony after two CW-TSCPC interventions. However, sample size and follow-up time are limited and, thus, this complication may have been missed. The cumulative energy reached after the second operation is $\leq 150$ Joules ( $2 \mathrm{CW}$-TSCPC treatment sessions each with 15 laser spots, each laser spot was performed at 2'000 $\mathrm{mW}$ and for 2'500 ms), which could still be considered safe enough and not enhance the risk of hypotony. Aujla et al. found the cumulative energy after CW-TSCPC as a risk factor for hypotony. They found a cutoff of $>190$ Joules for eyes developing hypotony, while eyes which received less cumulative energy did not develop hypotony [39].

\section{Conclusion}

The second CW-TSCPC treatment for patients with refractory glaucoma demonstrated safe and effective and non-inferior to the first CW-TSCPC treatment. Therefore, a second CW-TSCPC treatment should be considered a valid option when trying to further lower IOP after a first CW-TSCPC treatment failed to achieve the target IOP.
Authors' contributions MTH designed the study. EB collected the data. MTH and EB analyzed the data. MTH and EB interpreted the data. EB drafted the first version of the manuscript, and all authors commented on previous versions of the manuscript. MTH and EB read and approved the final version of the manuscript and agreed to be accountable for all aspects of the work.

Funding Open access funding provided by University of Zurich. No Funding.

Availability of data and material The data supporting this study's findings are available from the corresponding author upon reasonable request and within national and international laws.

Code availability Not applicable.

\section{Declarations}

Conflict of interest EB: None. MTH: Allergan / Abbvie: Consultant/Advisor, Lecture Fees; Eyelight: Consultant/Advisor; ELT Sight: Consultant/Advisor; Glaukos Corporation: Lecture Fees; Heidelberg Engineering: Lecture Fees; IRIDEX: Consultant/Advisor, Lecture Fees, Travel Reimbursement, Research Grant; MLase AG: Consultant/Advisor, Lecture Fees; Novartis, Alcon Pharmaceuticals: Lecture Fees; Reichert: Consultant/Advisor, Lecture Fees; Santen, Inc.: Consultant/Advisor, Lecture Fees, Research Grant; Théa Pharma: Lecture Fees. MTH is a consultant for Iridex. In addition, he received lecture fees and travel reimbursement from Iridex.

Ethical approval The study was approved by the local ethics committee (cantonal ethics committee of the canton of Zurich, registration ID 2020-00,219).

Consent to participate Patients who decided not to participate in research (negative general consent) were excluded. Consent for publication. Data from patients with a valid signed general consent were included. In cases, a general consent or a negative general consent was not available, an informed consent was obtained. Not applicable.

Open Access This article is licensed under a Creative Commons Attribution 4.0 International License, which permits use, sharing, adaptation, distribution and reproduction in any medium or format, as long as you give appropriate credit to the original author(s) and the source, provide a link to the Creative Commons licence, and indicate if changes were made. The images or other third party material in this article are included in the article's Creative Commons licence, unless indicated otherwise in a credit line to the material. If material is not included in the article's Creative Commons licence and your intended use is not permitted by statutory regulation or exceeds the permitted use, you will need to obtain permission directly from the copyright holder. To view a copy of this licence, visit http://creativecommons.org/licenses/by/4.0/. 


\section{References}

1. Casson RJ, Chidlow G, Wood JPM, Crowston JG, Goldberg I (2012) Definition of glaucoma: clinical and experimental concepts. Clin Experiment Ophthalmol 40(4):341-349. https://doi.org/10.1111/j.1442-9071. 2012.02773.x

2. Lee JWY, Chan PP, Zhang X, Chen LJ, Jonas JB (2019) Latest developments in normal-pressure glaucoma: diagnosis, epidemiology, genetics, etiology, causes and mechanisms to management. Asia-Pacific J. Ophthalmol. (Philadelphia, Pa.) 8(6):457-468. https://doi.org/ 10.1097/01.APO.0000605096.48529.9c.

3. Agarwal R, Gupta SK, Agarwal P, Saxena R, Agrawal SS (2009) Current concepts in the pathophysiology of glaucoma. Indian J Ophthalmol 57(4):257-266. https:// doi.org/10.4103/0301-4738.53049

4. Töteberg-Harms M, Rosentreter A, Lappas A, Funk J, Dietlein TS (2015) Current aspects on the management of normal tension glaucoma. Ophthalmologe 112(11):943-946. https://doi.org/10.1007/ s00347-015-0140-5

5. Jonas JB, Aung T, Bourne RR, Bron AM, Ritch R, Panda-Jonas S (2017) Glaucoma. Lancet (London, England) 390(10108):2183-2193. https://doi.org/10.1016/ S0140-6736(17)31469-1

6. Höhn R et al (2018) Prevalence of glaucoma in Germany: results from the Gutenberg Health Study. Graefe's Arch Clin Exp Ophthalmol 256(9):1695-1702. https:// doi.org/10.1007/s00417-018-4011-Z

7. Tham Y-C, Li X, Wong TY, Quigley HA, Aung T, Cheng C-Y (2014) Global Prevalence of Glaucoma and Projections of Glaucoma Burden through 2040: A Systematic Review and Meta-Analysis. Ophthalmology 121(11):2081-2090. https://doi.org/10.1016/j.ophtha. 2014.05.013

8. Flaxman SR et al (2017) Global causes of blindness and distance vision impairment 1990-2020: a systematic review and meta-analysis. Lancet Glob Heal 5(12):e1221e1234. https://doi.org/10.1016/S2214-109X(17)30393-5

9. Quigley HA, Broman AT (2006) The number of people with glaucoma worldwide in 2010 and 2020. Br J Ophthalmol 90(3):262-267. https://doi.org/10.1136/bjo. 2005.081224

10. Parihar JKS (2016) Glaucoma: The 'Black hole' of irreversible blindness. Med J Armed Forces India 72(1):34. https://doi.org/10.1016/j.mjafi.2015.12.001.

11. Mantravadi AV, Vadhar N (2015) Glaucoma. Prim Care Clin Off Pract 42(3):437-449. https://doi.org/10.1016/j. pop. 2015.05 .008

12. Weinreb RN, Aung T, Medeiros FA (2014) The pathophysiology and treatment of glaucoma: a review. JAMA 311(18):1901-1911. https://doi.org/10.1001/jama.2014. 3192

13. Meier-Gibbons F, Berlin MS, Töteberg-Harms M (2019) Influence of new treatment modalities on adherence in glaucoma. Curr Opin Ophthalmol 30(2):104-109. https://doi.org/10.1097/ICU.0000000000000551

14. M. Wu et al., "Evaluating Glaucoma Treatment Effect on Intraocular Pressure Reduction Using Propensity
Score Weighted Regression.,"Sci. Rep., vol. 9, no. 1, p. 15496, Oct. 2019, doi: https://doi.org/10.1038/ s41598-019-52052-5.

15. Lusthaus J, Goldberg I (2019) Current management of glaucoma. Med J Aust 210(4):180-187. https://doi.org/ $10.5694 / \mathrm{mja} 2.50020$

16. L. P. Cohen and L. R. Pasquale, "Clinical characteristics and current treatment of glaucoma.," Cold Spring Harb. Perspect. Med., vol. 4, no. 6, Jun. 2014, doi: https://doi. org/10.1101/cshperspect.a017236.

17. Ostler E, Rhee D, Burney E, Sozeri Y (2021) Advances in medical therapy for glaucoma. Curr Opin Ophthalmol 32(2):129-133. https://doi.org/10.1097/ICU.00000 00000000740

18. Conlon R, Saheb H, Ahmed IIK (2017) Glaucoma treatment trends: a review. Can J Ophthalmol 52(1):114124. https://doi.org/10.1016/j.jcjo.2016.07.013

19. Jurjevic D, Funk J, Töteberg-Harms M (2019) Cyclodestructive procedures to lower intraocular pressure - a review. Klin Monbl Augenheilkd 236(1):63-68. https:// doi.org/10.1055/s-0043-105271

20. Schuster AK, Erb C, Hoffmann EM, Dietlein T, Pfeiffer N (2020) The diagnosis and treatment of glaucoma. Dtsch Arztebl Int 117(13):225-234. https://doi.org/10. 3238/arztebl.2020.0225

21. Greslechner R, Spiegel D (2019) Laser trabeculoplasty in modern glaucoma therapy - a review. Klin Monbl Augenheilkd 236(10):1192-1200. https://doi.org/10. 1055/a-0577-7925

22. Douglas M, Gaasterland E (2021) Diode Laser Cyclophotocoagulation. Glaucoma Today. Accessed: Feb. 09, 2021. [Online]. Available: https://glaucomatoday.com/ articles/2009-mar/GT0309_05-php.

23. Gaasterland DE (2003) Regarding assessing G-Probe function. Eye 17(2):123-124. https://doi.org/10.1038/sj. eye. 6700286

24. Leszczyński R, Gierek-Lapińska A, FormińskaKapuścik M (2004) Transscleral cyclophotocoagulation in the treatment of secondary glaucoma. Med Sci Monit Int Med J Exp Clin Res 10(9): CR542-8.

25. Cheung JJC, Li KKW, Tang SWK (2019) Retrospective review on the outcome and safety of transscleral diode laser cyclophotocoagulation in refractory glaucoma in Chinese patients. Int Ophthalmol 39(1):41-46. https:// doi.org/10.1007/s10792-017-0782-1

26. Michelessi M, Bicket AK, Lindsley K (2018) Cyclodestructive procedures for non-refractory glaucoma. Cochrane Database Syst Rev 4(4):CD009313. https:// doi.org/10.1002/14651858.CD009313.pub2.

27. Fankhauser F, Kwasniewska S (2004) Cyclodestructive procedures. II. Optical fibers, endoscopy, physics: a review. Ophthalmol J Int d'ophtalmologie Int J Ophthalmol Zeitschrift fur Augenheilkd 218(3):147-161. https://doi.org/10.1159/000076839.

28. Iliev ME, Gerber S (2007) Long-term outcome of transscleral diode laser cyclophotocoagulation in refractory glaucoma. Br J Ophthalmol 91(12):1631-1635. https:// doi.org/10.1136/bjo.2007.116533

29. Gaasterland DE, Pollack IP (1992) Initial experience with a new method of laser transscleral 
cyclophotocoagulation for ciliary ablation in severe glaucoma. Trans Am Ophthalmol Soc 90:225-226

30. Chen MF, Kim CH, Coleman AL (2016) Cyclodestructive procedures for refractory glaucoma. Cochrane Database Syst Rev (3). https://doi.org/10.1002/14651858.cd012223.

31. Osman EA, Al-Muammar A, Mousa A, Al-Mezaine H, Al-Obeidan SA (2010) Controlled Cyclophotocoagulation with diode laser in refractory glaucoma and long term follow up at King Abdulaziz University Hospital, Riyadh. Saudi J Ophthalmol Off J Saudi Ophthalmol Soc 24(1):913. https://doi.org/10.1016/j.sjopt.2009.12.002.

32. Ramli N, Htoon HM, Ho CL, Aung T, Perera S (2012) Risk factors for hypotony after transscleral diode cyclophotocoagulation. J Glaucoma 21(3):169-173. https://doi. org/10.1097/IJG.0b013e318207091a

33. Rasmuson E, Lindén C, Lundberg B, Jóhannesson G (2019) Efficacy and safety of transscleral cyclophotocoagulation in Swedish glaucoma patients. Acta Ophthalmol 97(8):764-770. https://doi.org/10.1111/aos.14125

34. Wilensky JT, Kammer J (2004) Long-term visual outcome of transscleral laser cyclotherapy in eyes with ambulatory vision. Ophthalmology 111(7):1389-1392. https://doi.org/ 10.1016/j.ophtha.2003.11.008

35. S. Souissi et al. (2020) An update on continuous-wave cyclophotocoagulation (CW-CPC) and micropulse transscleral laser treatment (MP-TLT) for adult and paediatric refractory glaucoma. Acta Ophthalmol https://doi.org/10. 1111/aos.14661.
36. Kroon HM, Breslau PJ, Lardenoye JWHP (2007) Can the incidence of unplanned reoperations be used as an indicator of quality of care in surgery? Am J Med Qual Off J Am Coll Med Qual 22(3):198-202. https://doi.org/10. $1177 / 1062860607300652$

37. Hsia YC et al (2017) Early Reoperation Rate, Complication, and Outcomes in Resident-performed Glaucoma Surgery. J Glaucoma 26(2):87-92. https://doi.org/10.1097/ IJG.0000000000000533

38. Chu C-K, Liebmann JM, Cioffi GA, Blumberg DM, AlAswad LA (2020) Reoperations for Complications Within 90 Days After Glaucoma Surgery. J Glaucoma 29(5):344346. https://doi.org/10.1097/IJG.0000000000001484

39. Aujla JS, Lee GA, Vincent SJ, Thomas R (2013) Incidence of hypotony and sympathetic ophthalmia following trans-scleral cyclophotocoagulation for glaucoma and a report of risk factors. Clin Experiment Ophthalmol 41(8):761-772. https://doi.org/10.1111/ceo.12088

Publisher's Note Springer Nature remains neutral with regard to jurisdictional claims in published maps and institutional affiliations. 